\title{
Boron nitride supported Pt catalyst for selective hydrogenation
}

\author{
Jeffrey C.S. Wu ${ }^{\mathrm{a}, *}$, Chao-Yu Chen ${ }^{\mathrm{a}}$, and Shawn D. Lin ${ }^{\mathrm{b}}$ \\ ${ }^{a}$ Department of Chemical Engineering, National Taiwan University, Taipei, 10617 Taiwan, R.O.C \\ ${ }^{\mathrm{b}}$ Department of Chemical Engineering and Material Science, Yuan Zen University, Chung-Li, 320 Taiwan, R.O.C
}

Received 11 January 2005; accepted 19 April 2005

\begin{abstract}
A novel boron nitride (BN) supported Pt catalyst showed a special catalytic behavior in the selective hydrogenation of $\alpha$-, $\beta$ unsaturated aldehyde compared with a traditional $\mathrm{Pt} / \gamma-\mathrm{Al}_{2} \mathrm{O}_{3}$ catalyst. The hydrogenation of crotonaldehyde was carried out using a mixture of $\mathrm{H}_{2}$ /crotonaldehyde molar ratio 59 at temperature range from 30 to $300{ }^{\circ} \mathrm{C}$. $\mathrm{Pt} / \mathrm{BN}$ gave near $100 \%$ selectivity of butyraldehyde in the temperature range of $30-100{ }^{\circ} \mathrm{C}$ while $\mathrm{Pt} / \gamma-\mathrm{Al}_{2} \mathrm{O}_{3}$ showed a favorable selectivity of crotyl alcohol. Butyraldehyde was the main product on $\mathrm{Pt} / \mathrm{BN}$ because the $\mathrm{C}=\mathrm{C}$ bond of crotonaldehyde was preferentially hydrogenated at low temperature due to the support effect. BN possess graphite-like structure as an inert support and may repel $\mathrm{C}=\mathrm{O}$ end of crotonaldehyde during hydrogenation. The products distribution transited from kinetic to thermodynamic control with increasing temperature, and finally the hydrogenation became thermodynamically dominant at $250-300{ }^{\circ} \mathrm{C}$
\end{abstract}

KEY WORDS: boron nitride; crotonaldehyde; non-oxide support; Pt; selective hydrogenation.

\section{Introduction}

Materials traditionally used as supports are insulating oxides such as $\mathrm{SiO}_{2}, \gamma-\mathrm{Al}_{2} \mathrm{O}_{3}$, silica-alumina, and various zeolites. These oxides possess large surface area, numerous acidic/basic sites, and metal-support interaction that offer particular catalytic activity for many reactions. Metal oxides have also been thoroughly studied and employed in the chemical industry for decades.

The graphite-like hexagonal boron nitride $(\mathrm{BN})$ is the most stable $\mathrm{BN}$ isomer under ambient conditions [1]. Boron nitride has large thermal conductivity, superior temperature stability and acid-base resistance. In general, $\mathrm{BN}$ is inert material for catalytic reaction. In a supported metal system such as $\mathrm{Pt} / \mathrm{BN}, \mathrm{BN}$ support has been shown to have a negligible interaction with $\mathrm{Pt}$ in the catalytic oxidation [2,3]. In addition, the hydrophobicity of $\mathrm{BN}$ is the contrary to the conventionally used hydrophilic oxide support. Both the absence of $\mathrm{Pt}-$ $\mathrm{BN}$ support interaction and the hydrophobicity of $\mathrm{BN}$ may result in a different behavior in the selective hydrogenation.

The selective hydrogenation of $\alpha$-, $\beta$-unsaturated aldehyde into unsaturated alcohol is an important process in pharmaceutical, fine chemical, and fragrance industries [4]. Figure 1 depicts the reaction paths of $\alpha, \beta$ hydrogenation of crotonaldehyde. The product is either crotyl alcohol or butyraldehyde via the route of $\mathrm{C}=\mathrm{O}$ or $\mathrm{C}=\mathrm{C}$ hydrogenation, respectively. Based on Gibbs free energy calculation, butyraldehyde is favorable product of crotonaldehyde hydrogenation. Equations 1 and 2

\footnotetext{
* To whom correspondence should be addressed.
}

E-mail: cswu@ntu.edu.tw show the Gibbs free energies and equilibrium constants of butyraldehyde and crotyl alcohol from crotonaldehyde hydrogenation at $298 \mathrm{~K}$, respectively [5]. The equilibrium constant of butyraldehyde is 11 order of magnitudes higher than that of crotyl alcohol. Butanol can be formed with further hydrogenation of either butyraldehyde or crotyl alcohol. The selectivity of crotyl alcohol or butyraldehyde depends on the preferential adsorption of $\mathrm{C}=\mathrm{O}$ or $\mathrm{C}=\mathrm{C}$ on the active sites of a catalyst. The surface nature of support and Pt should play important roles in such selective hydrogenation.

$$
\begin{aligned}
\mathrm{CH}_{3} \mathrm{CH} & =\mathrm{CHCHO}+\mathrm{H}_{2} \stackrel{K_{1}}{\longleftrightarrow} \mathrm{CH}_{3} \mathrm{CH}_{2} \mathrm{CH}_{2} \mathrm{CHO} \\
G_{1} & =-138.6 \mathrm{~kJ} / \mathrm{mol}, \quad K_{1}=2.0 \times 10^{24} \\
\mathrm{CH}_{3} \mathrm{CH} & =\mathrm{CHCHO}+\mathrm{H}_{2} \stackrel{K_{2}}{\longleftrightarrow} \mathrm{CH}_{3} \mathrm{CH}=\mathrm{CHCH}_{2} \mathrm{OH} \\
G_{2} & =-77.3 \mathrm{~kJ} / \mathrm{mol}, \quad K_{2}=3.6 \times 10^{13}
\end{aligned}
$$

We therefore chose crotonaldehyde hydrogenation as a probing reaction to investigate the unique catalytic property provided by a novel BN support. The characteristics of $\mathrm{BN}$ supported $\mathrm{Pt}$ was examined in relation to the activity/selectivity of the catalysts for the hydrogenation of the $\mathrm{C}=\mathrm{O}$ and $\mathrm{C}=\mathrm{C}$ bonds in the vapor phase hydrogenation of crotonaldehyde.

\section{Experiment}

\subsection{Catalyst preparation}

Hexagonal-BN was obtained from High Performance Materials Inc., (Taiwan). It was crystallized at roughly 


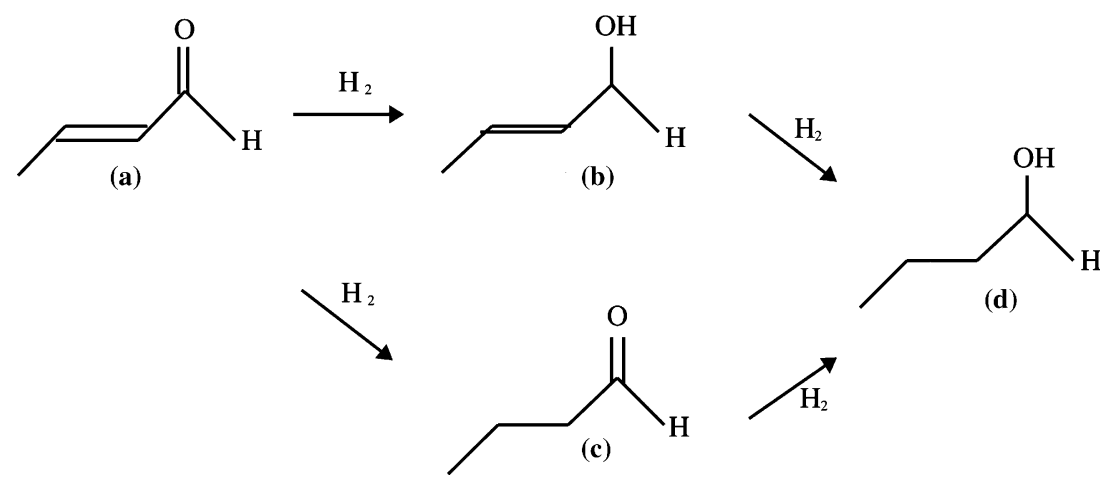

Figure 1. The reaction routes of crotonaldehyde hydrogenation, (a) crotonaldehyde (b) crotyl alcohol (c) butyraldehyde (d) butanol.

$800{ }^{\circ} \mathrm{C}$ during synthesis, a temperature lower than the typical $1000^{\circ} \mathrm{C}$. Gamma alumina $\left(\gamma-\mathrm{Al}_{2} \mathrm{O}_{3}\right)$, a commonly used oxide support, obtained from Merck (USA), was used for comparison. Precursor salt, $\mathrm{H}_{2} \mathrm{PtCl}_{6} \cdot 6 \mathrm{H}_{2} \mathrm{O}$, with approximately $40 \mathrm{wt} . \%$ platinum was purchased from Alfa Aesar (USA). Methanol was chosen as the diluting solvent for improved soaking of the hydrophobic BN support. The supported Pt catalysts were prepared utilizing the incipient wetness method. The quantity of methanol required to completely fill the support's pore volume was predetermined. Calculated amounts of $\mathrm{Pt}$ precursor salt was dissolved in methanol to obtain the desired metal loading. After applying the incipient wetness process, the catalysts were dried in a hood at room temperature for $24 \mathrm{~h}$, then reduced at $450{ }^{\circ} \mathrm{C}$ in flowing gas mixture $\left(\mathrm{H}_{2} / \mathrm{He}=0.25\right)$ of $15 \mathrm{ml} / \mathrm{min}$ for $2 \mathrm{~h}$ referred as fresh catalysts. The catalysts were prepared as $0.37 \mathrm{wt} \% \mathrm{Pt} / \mathrm{BN}$ and 0.37 wt. $\% \mathrm{Pt} / \gamma-\mathrm{Al}_{2} \mathrm{O}_{3}$. The detailed incipient wetness procedure is described in literature [6].

The specific surface area of the support was measured by $\mathrm{N}_{2}$ adsorption in the Micromeritics ASAP 2010. Fresh catalyst was $\mathrm{H}_{2}$ reduced at $300{ }^{\circ} \mathrm{C}$ for $2 \mathrm{~h}$ before chemisorption. The $\mathrm{H}_{2}$ chemisorption procedure was similar to that described by Yang and Goodwin [7]. The amount of irreversible $\mathrm{H}_{2}$ chemisorption was taken to determine the Pt dispersion.

\subsection{Hydrogenation Reaction}

Figure 2 depicts the schematic of reactor system for hydrogenation. Fresh catalyst $(0.3 \mathrm{~g})$ was charged in the middle of a straight-tube quartz reactor with a $16-\mathrm{mm}$ ID. The catalyst was first oxidized in air stream at $300{ }^{\circ} \mathrm{C}$ to remove adsorbed VOCs during storage, then purged with $\mathrm{He}$ for $30 \mathrm{~min}$ and switched to pure hydrogen $(99.999 \%)$ ). The temperature was increased to $450{ }^{\circ} \mathrm{C}$ for $1 \mathrm{~h}$ to reduce the catalyst in the reactor, then cooled to ambient temperature before switching to reactant mixture. The reactant mixture was composed by flowing pure hydrogen into a saturator filled with liquid crotonaldehyde. Crotonaldehyde (98\%) was purchased from Fluka. The concentration of crotonaldehyde in the reactant mixture can be adjusted by tuning the saturator temperature, and confirmed by an on-line $\mathrm{GC}$ before reaction. The molar ratio of $\mathrm{H}_{2} /$ crotonaldehyde mixture was maintained at 59 and passed through the reactor at $50 \mathrm{ml} / \mathrm{min}$ under atmospheric pressure. The reaction temperature increased from 30 to $300{ }^{\circ} \mathrm{C}$ in a tubular furnace. A thermocouple was placed in the center of the catalyst bed to record the reaction temperature and also control the furnace. All gas lines were wrapped with heating tapes and maintained warm to prevent any condensation. The products were measured by an on-line GC (HP GC6890) equipped with $30 \mathrm{~m}$ HP-Innowax capillary column using flame ionization detector. The activities of catalyst were measured after achieving steady-state at $30{ }^{\circ} \mathrm{C}$ initially. Usually an entire reaction lasted $4-6 \mathrm{~h}$ to evaluate a fresh catalyst without noticeable deactivation. The conversion and product selectivity were calculated using Eqs. 3 and 4.

conversion $(\%)$

$=\frac{\mathrm{C}_{\text {crotonaldehyde Input }}-\mathrm{C}_{\text {crotonaldehyde }} \text { Output }}{\mathrm{C}_{\text {crotonaldehyde }} \text { Input }} \times 100 \%$

selectivity (\%)

$$
=\frac{\mathrm{C}_{\text {product }}}{\mathrm{C}_{\text {crotonaldehyde }} \text { Input }-\mathrm{C}_{\text {crotonaldehyde }} \text { Output }} \times 100 \%
$$

\section{Results and discussion}

Table 1 lists the physical properties and the amount of $\mathrm{H}_{2}$ chemisorption of $\mathrm{Pt} / \mathrm{BN}$ and $\mathrm{Pt} / \gamma-\mathrm{Al}_{2} \mathrm{O}_{3}$ catalysts. The particle size of $\mathrm{Pt} / \mathrm{BN}$ was in the range from 0.4 to $90 \mu \mathrm{m}$, and that of $\mathrm{Pt} / \gamma-\mathrm{Al}_{2} \mathrm{O}_{3}$ was 6-190 $\mu \mathrm{m}$ using laser-light scattering method. The $\mathrm{Pt}$ dispersion of catalyst can be expressed by the $\mathrm{H} / \mathrm{Pt}$ ratio. The $\mathrm{Pt}$ dispersion of $\mathrm{Pt} / \gamma-\mathrm{Al}_{2} \mathrm{O}_{3}$ was 0.24 higher than that of $\mathrm{Pt} /$ $\mathrm{BN}$. Figure 3 shows conversions of crotonaldehyde hydrogenation from 30 to $300{ }^{\circ} \mathrm{C}$ on $\mathrm{Pt} / \mathrm{BN}$ and $\mathrm{Pt} /$ 


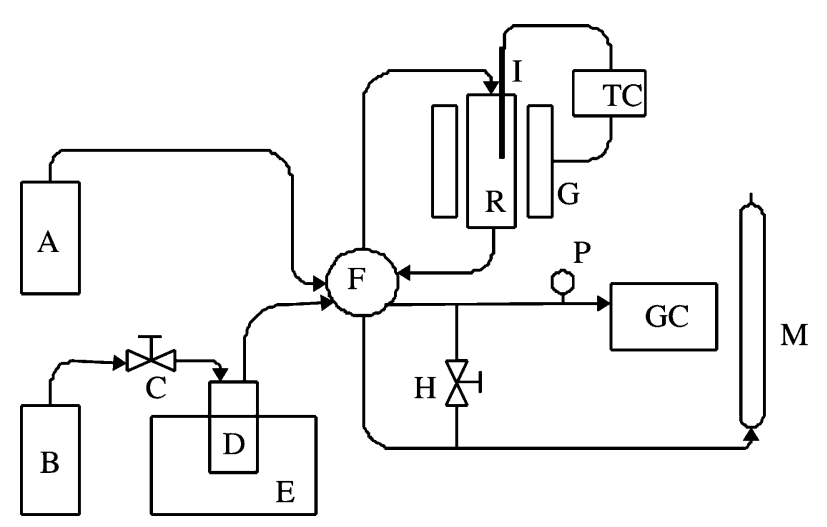

Figure 2. Schematic of hydrogenation system, A, purge gas; B, hydrogen; C, metering valve; D, crotonaldehyde saturator; E, water bath; F, 6way valve; G, tubular furnace; $\mathrm{H}$, valve; I, thermocouple; P, pressure gauge; R, tubular reactor; GC, gas chromatography; TC, temperature controller.

Table 1

Properties and $\mathrm{H}_{2}$ chemisorption of Pt catalysts

\begin{tabular}{lcccc}
\hline Catalyst & Specific area $\left(\mathrm{m}^{2} / \mathrm{g}\right)$ & Mean particle size of support ${ }^{\mathrm{a}}(\mu \mathrm{m})$ & $\mathrm{H}_{2}$ uptake $^{\mathrm{b}}(\mu \mathrm{mol} / \mathrm{g})$ & $\mathrm{H} / \mathrm{Pt} \mathrm{ratio}^{\mathrm{c}}$ \\
\hline $0.37 \mathrm{wt} \% \mathrm{Pt} / \mathrm{BN}$ & 48.5 & 2.8 & 2.2 & 0.11 \\
$0.37 \mathrm{wt} \% \mathrm{Pt} / \gamma-\mathrm{Al}_{2} \mathrm{O}_{3}$ & 112.9 & 66.4 & 4.5 & 0.24 \\
\hline
\end{tabular}

${ }^{\text {a }}$ Measured by laser-light scattering method.

${ }^{\mathrm{b}}$ Irreversible hydrogen chemisorption.

${ }^{\mathrm{c}}$ Molar ratio of chemisorbed hydrogen to Pt loading.

$\gamma-\mathrm{Al}_{2} \mathrm{O}_{3}$. Complete conversions were achieved at 180 and $220{ }^{\circ} \mathrm{C}$ on $\mathrm{Pt} / \gamma-\mathrm{Al}_{2} \mathrm{O}_{3}$ and $\mathrm{Pt} / \mathrm{BN}$, respectively. The turnover frequency (TOF) of crotonaldehyde hydrogenation could be calculated based on the Pt dispersion. The TOF of $\mathrm{Pt} / \mathrm{BN}$ was ranged $0.004-0.09 \mathrm{~s}^{-1}$ from 30 to $100{ }^{\circ} \mathrm{C}$, and the TOF of $\mathrm{Pt} / \gamma-\mathrm{Al}_{2} \mathrm{O}_{3}$ was ranged 0.02 $0.19 \mathrm{~s}^{-1}$ from 30 to $100{ }^{\circ} \mathrm{C}$. Thus the activity of $\mathrm{Pt} / \gamma$ $\mathrm{Al}_{2} \mathrm{O}_{3}$ was higher than that of $\mathrm{Pt} / \mathrm{BN}$ over the same temperature range. The apparent activation energies of

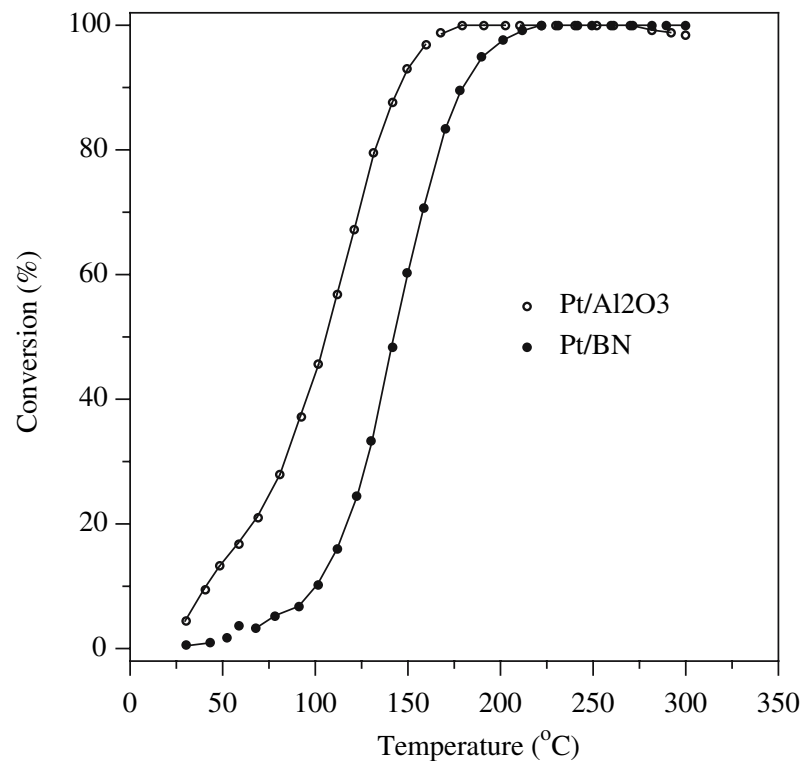

Figure 3. Conversion of crotonaldehyde hydrogenation. crotonaldehyde hydrogenation on $\mathrm{Pt} / \mathrm{BN}$ and $\mathrm{Pt} / \gamma$ $\mathrm{Al}_{2} \mathrm{O}_{3}$ were $42.4 \pm 3.4$ and $48.3 \pm 2.0 \mathrm{~kJ} / \mathrm{mol}$, respectively, estimated by using the data of reaction conversion less than $10 \%$ via the Arrhenius equation.

Figures 4 and 5 show the product selectivities of crotonaldehyde hydrogenation from 30 to $300{ }^{\circ} \mathrm{C}$ on $\mathrm{Pt} / \mathrm{BN}$ and $\mathrm{Pt} / \gamma-\mathrm{Al}_{2} \mathrm{O}_{3}$, respectively. All hydrogenated products, crotyl alcohol, butyraldehyde, and butanol were found over the reaction temperature range on both catalysts. The products distribution was significantly different between $\mathrm{Pt} / \mathrm{BN}$ and $\mathrm{Pt} / \gamma-\mathrm{Al}_{2} \mathrm{O}_{3}$. At low conversion, near $100 \%$ butyraldehyde was produced on $\mathrm{Pt} / \mathrm{BN}$ while $\mathrm{Pt} / \gamma-\mathrm{Al}_{2} \mathrm{O}_{3}$ gave mostly crotyl alcohol. Almost no crotyl alcohol was produced on $\mathrm{Pt} / \mathrm{BN}$ over the whole temperature range. Butanol was produced with further hydrogenation of either butyraldehyde or crotyl alcohol (as shown in figure 1), and was found on both catalysts. However, butanol was diminished due to thermodynamic unfavorable at high temperature. Butyraldehyde became the ultimate product of hydrogenation on both catalysts at higher temperature $\left(>250{ }^{\circ} \mathrm{C}\right)$ because of thermodynamic equilibrium.

Butyraldehyde is thermodynamically and kinetically favored over crotyl alcohol in crotonaldehyde hydrogenation [8]. Most Pt catalysts were found to simultaneously produce both butyraldehyde and crotyl alcohol. Many efforts have been to fight thermodynamic and kinetic barriers to make more crotyl alcohol. These include changing the electronic property of $\mathrm{Pt}$, alloying 


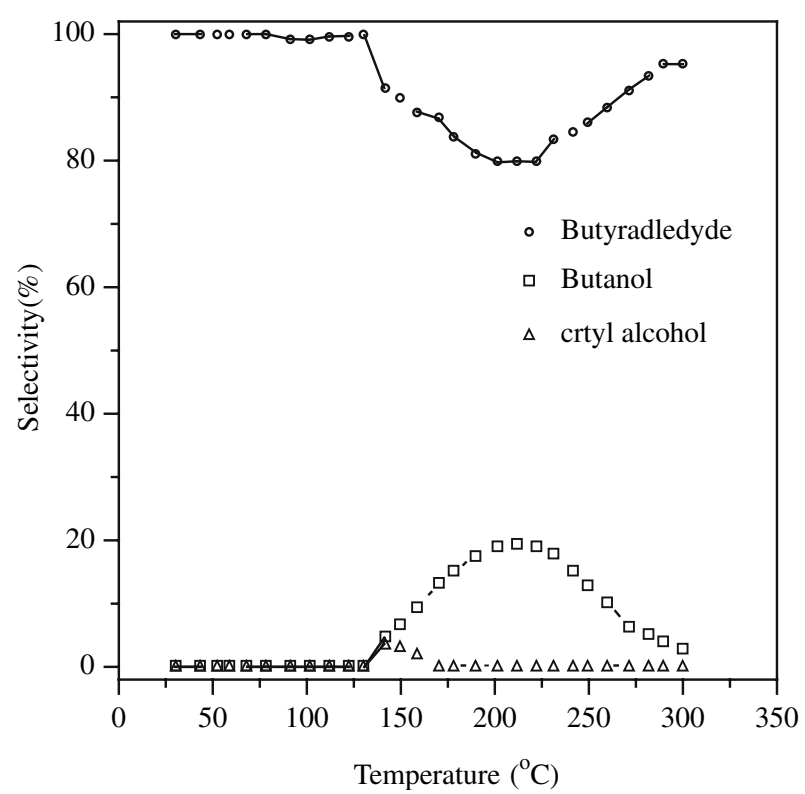

Figure 4. Conversion and product selectivity of crotonaldehyde on $\mathrm{Pt} / \mathrm{BN}$.

$\mathrm{Pt}$, and/or inducing certain metal-support interaction. Support effect was reported in many earlier studies to boost the selectivity toward crotyl alcohol [9-13]. BN, as the support in this study, shows a support effect toward the other extreme. It almost completely shut off the formation of crotyl alcohol. Coloma et al. [14] reported that $\mathrm{Pt} / \mathrm{Carbon}$ can show a selectivity to crotyl alcohol below 5\% if carbon support had no oxygen groups. However, these authors attributed such an observation to a Pt dispersion effect because that a higher Pt dispersion was achieved when the same carbon support contained oxygen groups and that a higher crotyl alcohol selectivity was found with these $\mathrm{Pt} /$ Carbon(oxidized). The $\mathrm{Pt}$ dispersion effect in crotonaldehyde hydrogenation is somewhat controversial. Vannice and coworkers [8,9] considered that the Pt dispersion had little effect on the product selectivity; whereas, Englisch et al. [10] reported that a higher crotyl selectivity was found when Pt dispersion was lower. Nevertheless, neither indicates that at a low Pt dispersion as 0.11 as our $\mathrm{Pt} / \mathrm{BN}$ can shut off the formation of crotyl alcohol. Therefore, the low crotyl alcohol selectivity in our $\mathrm{Pt} / \mathrm{BN}$ and in $\mathrm{Pt} /$ Carbon (without oxygen group) [14] must be due to the unique support property. Both $\mathrm{BN}$ and carbon have their basal planes as graphite structure. Such surfaces may repel $\mathrm{C}=\mathrm{O}$ end of crotonaldehyde and help to preserve it during hydrogenation. Such an effect may also explain the lower butanol selectivity than the butyraldehyde selectivity in our $\mathrm{Pt} /$ $\mathrm{BN}$ (figure 4). It can be attributed that the $\mathrm{C}=\mathrm{O}$ end was so protected that the further hydrogenation of butyraldehyde to butanol was suppressed.

The difference of products distribution between $\mathrm{Pt} / \mathrm{BN}$ and $\mathrm{Pt} / \gamma-\mathrm{Al}_{2} \mathrm{O}_{3}$ was related to the support

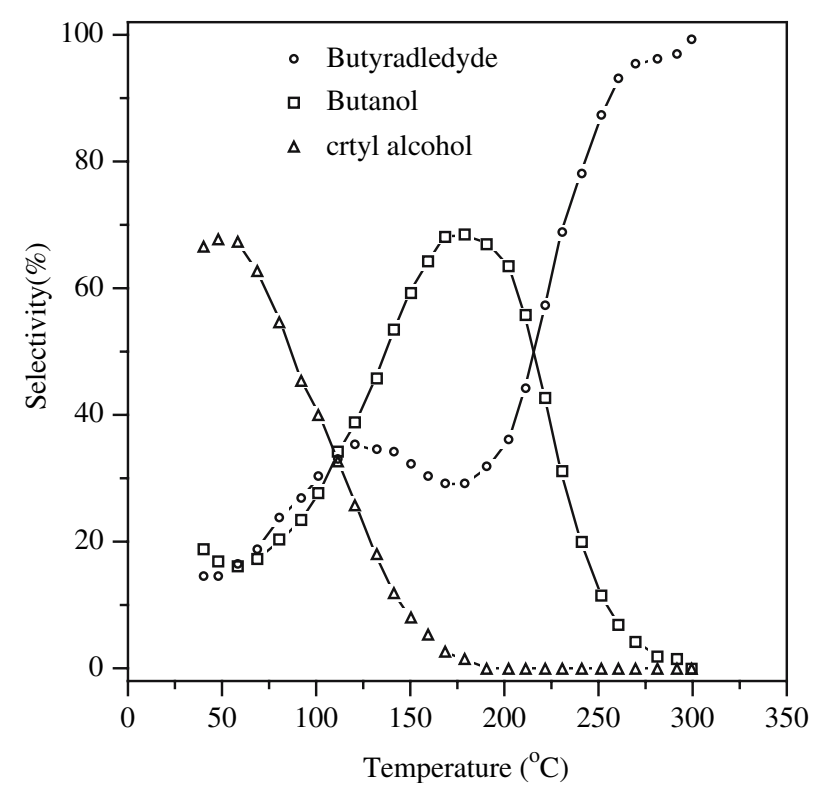

Figure 5. Conversion and product selectivity of crotonaldehyde on $\mathrm{Pt} / \gamma-\mathrm{Al}_{2} \mathrm{O}_{3}$.

characteristics. $\mathrm{Pt} / \gamma-\mathrm{Al}_{2} \mathrm{O}_{3}$ held a metal-support interaction, which was proved to favor $\mathrm{C}=\mathrm{O}$ hydrogenation [13]. The Pt on $\gamma-\mathrm{Al}_{2} \mathrm{O}_{3}$ was slightly positively charged due to the interaction with support. The $\mathrm{C}=\mathrm{O}$ group of crotonaldehyde molecule would be preferentially closed $\mathrm{Pt}$ site because of its abundant electrons. Thus, crotyl alcohol was favorably produced via $\mathrm{C}=\mathrm{O}$ hydrogenation. On the other hand, BN was nearly an inert support thus $\mathrm{Pt} / \mathrm{BN}$ favors to hydrogenate $\mathrm{C}=\mathrm{C}$. The chemical state of $\mathrm{Pt}$ on $\mathrm{BN}$ could be easily maintained at metal status $\mathrm{Pt}^{0}$ [2]. Consequently butyraldehyde was mostly produced from crotonaldehyde via the easy route of $\mathrm{C}=\mathrm{C}$ hydrogenation on $\mathrm{Pt}$ site.

At low temperature $\left(<100{ }^{\circ} \mathrm{C}\right)$, reaction routes were governed by kinetics so that butyraldehyde was the major product on $\mathrm{Pt} / \mathrm{BN}$, and most crotyl alcohol was produced on $\mathrm{Pt} / \gamma-\mathrm{Al}_{2} \mathrm{O}_{3}$. When the reaction temperature increased, the activity of $\mathrm{Pt}$ increased so that both hydrogenation rates of $\mathrm{C}=\mathrm{C}$ and $\mathrm{C}=\mathrm{O}$ gradually exceed the feed rate of crotonaldehyde under our experimental conditions. The hydrogenation of crotonaldehyde progressively transited from kinetic to thermodynamic control on both catalysts with increasing temperature. Consequently, the products distribution was then contributed by both kinetics and thermodynamics at median temperature range $\left(120-250^{\circ} \mathrm{C}\right)$, so butanol emerged as one of products. As shown in figures 4 and 5 , that $\mathrm{Pt} / \gamma-\mathrm{Al}_{2} \mathrm{O}_{3}$ shifted to higher selectivity of butanol than that of $\mathrm{Pt} / \mathrm{BN}$ may be attributed to the higher specific activity of $\mathrm{Pt}$ on $\gamma-\mathrm{Al}_{2} \mathrm{O}_{3}$ support. As shown in figure 3 , the specific activity of $\mathrm{Pt} / \gamma-\mathrm{Al}_{2} \mathrm{O}_{3}$ was higher than that of $\mathrm{Pt} / \mathrm{BN}$ due to $\mathrm{Pt}$ dispersion. The $\mathrm{Pt}$ sintering of $\mathrm{Pt} / \mathrm{BN}$ was more severe than that on $\mathrm{Pt} / \gamma-\mathrm{Al}_{2} \mathrm{O}_{3}$ during $\mathrm{H}_{2}$ reduction at $450{ }^{\circ} \mathrm{C}$ because of negligible 
metal-support interaction on BN. The Pt dispersion of $\mathrm{Pt} / \gamma-\mathrm{Al}_{2} \mathrm{O}_{3}$ was near twice higher than that of $\mathrm{Pt} / \mathrm{BN}$ (Table 1). Therefore, crotonaldehyde was more likely further hydrogenated to butanol on $\mathrm{Pt} / \gamma-\mathrm{Al}_{2} \mathrm{O}_{3}$. Finally, the hydrogenation was thermodynamically dominated at $250-300{ }^{\circ} \mathrm{C}$. The selective hydrogenation of catalyst was diminished. Butyraldehyde was the most favorable product because it was thermodynamically stable according to the calculated Gibb's free energy at elevated temperatures [9].

\section{Conclusion}

The selective hydrogenation of crotonaldehyde was performed by employing BN supported Pt catalyst. Boron nitride supported Pt catalyst exhibits a minimum metal-support interaction. In addition, BN possess basal planes as graphite structure. Active $\mathrm{Pt}$ sites on such surface may repel $\mathrm{C}=\mathrm{O}$ end of crotonaldehyde and help to preserve it during hydrogenation. Therefore, near $100 \%$ butyraldehyde was produced in crotonaldehyde hydrogenation using $\mathrm{Pt} /$ BN catalyst at low temperature range. The products distribution was shifted from kinetic to thermodynamic control with increasing temperature resulting in increasing the selectivity of butanol. The final stable product was butyraldehyde in both $\mathrm{Pt} / \mathrm{BN}$ and $\mathrm{Pt} / \gamma$ $\mathrm{Al}_{2} \mathrm{O}_{3}$ catalysts due to thermodynamic governing at high temperature. Although the specific activity of $\mathrm{Pt} /$ $\mathrm{BN}$ was lower than that of $\mathrm{Pt} / \gamma-\mathrm{Al}_{2} \mathrm{O}_{3}$ due to low $\mathrm{Pt}$ dispersion, $\mathrm{BN}$ can provide a special catalytic property in the selective hydrogenation. Therefore, boron nitride may be used as unique support material for industrial hydrogenation in the future.

\section{Acknowledgments}

The authors would like to thank the National Science Council of the Republic of China, Taiwan for financially supporting this research under Contract No. NSC-932214-E-002-030.

\section{References}

[1] S. Alkoy, C. Toy, T. Gonul and A. Tekin, J. Eur. Ceramic Soc. 17 (1997) 1415

[2] Z.-A. Lin, J.C.S. Wu, J.-W. Pan and C.-T. Yeh, J. Catal. 210 (2002) 39.

[3] J.C.S. Wu, Y.-C. Fan and C.-A. Lin, Ind. Eng. Chem. Res. 42 (2003) 3225.

[4] P. Gallezot and D. Richard, Catal. Rev.-Sci. Eng. 40 (1998) 81.

[5] B.E. Polling, J.M. Prausnitz and J.P. O'Connell, The Properties of Gases and Liquids, 5th ed., (McGraw-Hill, New York, 2000) pp. 3.15-3.40.

[6] J.C.S. Wu, Z.-A. Lin, J.-W. Pan and M.-H. Rei, Appl. Catal. A: Gen. 219 (2001) 117.

[7] C.H. Yang and J.G. Goodwin Jr., J. Catal. 78 (1982) 182.

[8] M.A. Vannice, J. Mol. Catal. 59 (1990) 165.

[9] M.A. Vannice and B. Sen, J. Catal. 115 (1989) 65.

[10] M. Englisch, A. Jentys and J.A. Lercher, J. Catal. 166 (1997) 25.

[11] K. Liberková and R. Touroude, J. Mol. Catal. A: Chem. 180 (2002) 221.

[12] P. Concepción, A. Corma, J. Silvestre-Albero, V. Franco and J.Y. Chane-Ching, J. Am. Chem. Soc. 126 (2004) 5523.

[13] M. Consonni, D. Jokic, D. Yu Murzin and R. Touroude, J. Catal. 188 (1999) 165.

[14] F. Coloma, A. Sepúlveda-Escribano and F. Rodríguez-Reinoso, Appl. Catal. A: Gen. 123 (1995) L1. 